\title{
Genetically-Modified Organisms in United States Agriculture: Mandate for Food Labeling
}

\author{
Sophia Armenakas ${ }^{1}$, Macrene Alexiades-Armenakas ${ }^{1,2}$ \\ ${ }^{1}$ Dermatology and Laser Surgery Center, New York, USA; ${ }^{2}$ Yale University School of Medicine, New Haven, USA. \\ Email: email@nyderm.org
}

Received May 29 $9^{\text {th }}$, 2013; revised June 29 $9^{\text {th }}, 2013$; accepted July $6^{\text {th }}, 2013$

Copyright (C) 2013 Sophia Armenakas, Macrene Alexiades-Armenakas. This is an open access article distributed under the Creative Commons Attribution License, which permits unrestricted use, distribution, and reproduction in any medium, provided the original work is properly cited.

\begin{abstract}
The production of foods with genetically modified organisms (GMOs) has risen rapidly over the past three decades to comprise nearly $90 \%$ of crops grown in the United States today. Currently, there are no mandates for labeling foods containing GMOs. GMO agricultural crops contain the insertion of genes encoding for pesticides, pesticide resistance, growth factors, or other substances not normally present. In addition to the foreign genes that are inserted, hundreds to thousands of mutations disrupt normal genes in GMO plants. Recently, animal studies have demonstrated toxicity of GMO foods causing organ failure, infertility, carcinomas and death. The FDA requirement of ingredients added to foods being labeled on the product is not applied to GMO foods, precluding the consumer's right to know. GMOs provide an economic incentive to companies because the seeds can be patented, driving up costs and creating the potential for monopolies. Herbicide-resistance conferred by GMOs has resulted in higher pesticide applications, which correlate with higher human cancer rates, and the emergence of pesticide-resistant weeds and insects. GMO toxins are spreading into non-target insects, waterways and aquatic organisms, with toxicity to non-target organisms and resultant contamination of disparate ecosystems in the food chain. The appropriateness of mandatory GMO labeling of foods in the United States is discussed.
\end{abstract}

Keywords: GMO; Agriculture; Genetically-Modified Organisms; Pesticides; Crops; Food; Labeling; GM; Transgene

\section{Introduction}

According to the United States Department of Agriculture, nearly ninety percent of the foods ingested in the United States (US) are produced with genetically modified organisms (GMOs) as shown in Figure 1 [1]. GMOs are organisms, including but not limited to plants, whose genetic material has been altered [2]. Since the first GMO plant was produced in 1987 and commercially introduced in 1996, agricultural companies have been using this method of genetic engineering to boost the immunity and heartiness of their seeds. GMO agricultural crop plants are typically infused with genes from other organisms conferring pesticide resistance or tolerance, or growth manipulation [3]. Antibiotic resistant genes are often used as a method of selecting for the plant cells that have been successfully modified, therefore introducing additional non-essential genes that also become part of the GMO plant [3].

The largest of the GMO producing companies is Monsanto ${ }$, a corporation that owns patents for seeds used for virtually all our foods, therefore introducing economic incentives and potential conflicts of interest [4]. Numerous examples of these patented GMO seeds include corn, sugar and soy, which comprise the basic ingredients of most US foods. Although the safety of these seeds has not been rigorously tested, the Food and Drug Administration (FDA) has determined that these antibiotic and exogenous gene-instilled foods are "substantially equivalent" to non-GMO foods, meaning that the composition of the transgenic food does not differ from the natural variety in a "meaningful way" [5-8]. On this basis, GMO labeling is currently not required in the US, which means that consumers are not informed when foods contain GMOs.

A number of animal studies have demonstrated toxicity of GMO foods. Recently, a randomized, controlled trial of rats fed GMO versus non-GMO maize demonstrated increased tumor formation and mortality in the GMO-fed animals [9]. Additional animal studies support this finding of GMO toxicity [10]. Furthermore, herbi- 


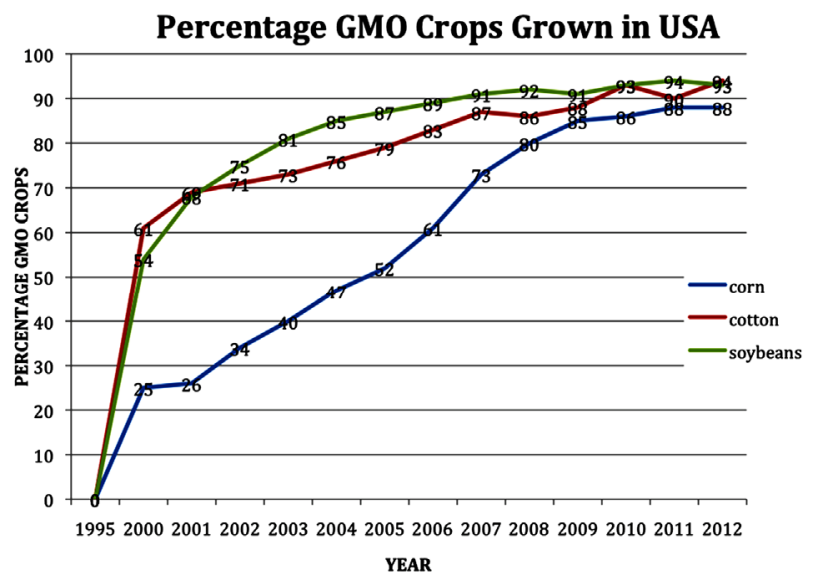

Figure 1. Percentage of GMO Crop Varieties 1996-2012. The percentage of crops in the US from GMO seeds since their introduction in 1996 has increased dramatically. Shown are the total percent GMO in the US for corn, cotton and soybeans. In the past two decades, GMOs have rapidly risen to comprise $88 \%, 94 \%$ and $93 \%$ of total corn, cotton and soybean crops, respectively, grown in the US as of 2012. Total GMO values were not recorded prior to 2000 and these values are assumed to be zero prior to the introduction of GMOs in 1996 (Adapted from USDA, Economic Research Service) [1].

cide-resistance conferred by GMOs has resulted in farmers applying higher amounts of pesticides, with resultant increased pesticide resistance among weeds and other organisms, as well as increased carcinogenesis from higher pesticide exposure [11]. The published reports of GMO toxicity, the rapid widespread implementation of GMOs, the lack of established long-term safety, the consumer's right to know and the near monopoly in GMO seed production provide compelling arguments for mandatory labeling of GMO-containing foods in the US.

\section{GMO Toxicity Studies}

\subsection{Transgene Products}

The primary safety concern associated with GMOs is toxicity. The foreign genetic material that is inserted into the plant genome is termed a transgene product. The transgene products, which include pesticide-resistance and pesticides, have not been subject to investigations regarding their safety when ingested by humans. Currently, there are no government regulations requiring an assessment of the short- or long-term safety of GMO food consumption. Consequently, US consumers have been ingesting foods containing these transgene products at a high rate.

Evidence for the toxicity of GMO foods has been put forth in a randomized, controlled trial demonstrating that rats fed GMO feed have a 2- to 3-fold increased risk of developing lethal tumors, liver and kidney disorders, and death [9]. No difference was detected in disease or death rates among rats given feed with and without pesticide application, indicating that the toxicity was due to the GMO transgene and not to exogenous pesticide application [9]. The GMO-fed rats demonstrated higher rates of tumor formation, liver and kidney toxicity, and mortality rates, as compared to non-GMO fed animals, which was statistically significant [9].

An additional study conducted on animals with GMO consumption has demonstrated decreased fertility, birth defects, neurologic problems, cancer, and alterations in liver and kidney function [10]. From that University of Caen study, rats that were fed a GMO diet developed mammary tumors and organ failure, resulting in premature death as compared to controls [10]. In view of these reports of toxicity in animal studies, long-term studies should now be performed on humans before universally embracing GMO products. Since these investigations will take many years to complete and GMO seeds have already flooded the market, at the very least, there should be mandatory labeling of GMO use.

\subsection{Insertion Site Disruption}

Additional sources for potential toxicity stem from the numerous insertion sites of GMO genes in the host plant genome, which may disrupt normal plant genes, further increasing the potential for toxicity [12]. Hundreds to thousands of mutations in normal genes are caused by the genetic engineering required to introduce the transgene to plants [12]. This results in plants that are dissimilar to native or non-GMO plants. One study reported that control plants display a "genetic similarity value" of $100 \%$; in contrast, this value is only $96 \%-98 \%$ for GMO plants [13]. The potential hazards of these extensive mutations in GMO plants are not known; however, such dissimilarity in the GMO genome as compared to natural controls provides a strong argument against the "substantial equivalence" determination by the FDA.

\section{Consumers Right to Know}

A second concern is the consumers' right to know the ingredients in the food they consume. Prior to GMOs, any ingredients added to a food were required to be printed on the ingredient label on the packaging [14]. With the advent of GMOs, such ingredients are inserted into the food, thereby bypassing this requirement to inform the consumer. The information on ingredient labels has protected consumers, enabling them to make an informed decision about what to buy and preventing the ingestion of toxic or allergenic ingredients. With the advent of GMOs, such consumer protections need to be updated to keep up with the pace of technology and include ingredients added to foods transgenically.

With mandatory GMO labeling, the sales of foods 
containing GMOs would be predicted to decrease as consumers are informed of what they are buying. Support for this argument comes from countries that require GMO labeling. In Europe, where GMO labeling is required, GMO-produced foods have nearly disappeared from the market [15]. In contrast, in the United States where labeling is not required, consumers unknowingly choose GMO-produced foods $90 \%$ of the time [1]. This demonstrates that consumers, when given a choice, select the non-GMO variety over GMO foods the vast majority of the time. GMO labeling is an important step to restore the consumer protections that ingredient listings provide and put the consumer in charge.

\section{Economic Incentives}

GMO seeds provide an unfair economic incentive to companies that develop them because, unlike natural seeds, they can be patented, driving up costs. This ability to patent seeds also creates the potential for a monopoly and eliminating competition, which further increases seed costs to farmers. Evidence for such a trend comes from Monsanto ${ }^{\circledR}$, the world's largest company that holds thousands of patents on numerous basic crop seeds [4]. During the past few decades, coinciding with GMO development, seed expenditures have increased dramatically [16]. In addition, Monsanto licensing agreements have barred farmers from storing seeds for the next year, forcing them to buy new seeds every year, or face highly publicized lawsuits.

The fundamental agricultural advantages of GMO seeds, including resistance to insects, weeds and drought, also provide incentive to farmers to choose the more profitable option of GMO use. Without freedom in the marketplace for competition between GMO and naturally produced food that GMO labeling would ensure, farmers are discouraged from using conventional seeds. By labeling GMO-containing products, competition will be restored to the marketplace as non-GMO demand will increase as has been shown in other markets, and natural seed farming will increase.

\section{GMO Risk-Benefit Analysis}

\subsection{Increased Food Production}

The justification used in support of GMOs is that they are needed to compensate for the population explosion of the last several decades. The increased population has created an exponential increase in food demand and rate of production. GMO seeds theoretically provide the means for increased food production, which may accelerate the availability of food for the close to one billion people in the world. By incorporating foreign genetic material, GMOs provide immunity and protection against potentially harmful diseases, thereby increasing yield as compared to conventional crops. These benefits have the potential to increase agricultural productivity and help alleviate the worldwide hunger burden.

\subsection{GMO Resistant Insects}

Even if these theoretical advantages prove true, the widespread use of GMOs eventuates in GMO-resistant pests. An established example of the acquired resistance phenomenon is the emergence of GMO-resistant insects [17]. This phenomenon results in the emergence of "super insects” from GMO’s strong selection pressure inducing the rapid genetic evolution of pesticide-resistance.

\subsection{Human Antibiotic-Resistance}

Similarly, antibiotic-resistance in humans may occur from ingestion of transgenic antibiotics in GMO plants. The unnecessary and excessive use of oral antibiotics is a well-known and universally accepted source of bacterial resistance. Antibiotic-embedded GMOs are a less evident potential cause of this problem. Immunotoxicity of transgene products and their inadvertent disruption of normal plant genes are additional potential hazards. GMO labeling, leading to their decreased use, may help prevent some of these concerns.

\subsection{GMO Resistant Weeds}

Herbicide-resistant GMO crops confer tolerance of crops to pesticides, such as glyphosate, resulting in increased application of such pesticides. The long-term conesquences include increased pesticide resistance among weeds and other organisms, and increased cancer rates among exposed humans and animals. Glyphosate-resistant weeds have increased rapidly since the introduction of GMOs [11].

\subsection{Increased Pesticide Application}

Since the introduction of herbicide-resistant GMO crops, the application of herbicides in the US has increased dramatically. Such consequences increase the costs of controlling resistant weeds, with herbicide costs increaseing nearly 3-fold [11]. A recent study demonstrated that herbicide application increased by 239 million kg (527 million pounds) in the US between 1996 and 2011 [11]. While the same study indicated a reduction in insecticide application by 56 million $\mathrm{kg}$ (123 million pounds) due to insecticide-instilled crops, the overall pesticide use increased by a net 183 million kg (404 million pounds) or $7 \%$ [11]. Thus, contrary to the claims that GMOs may serve to decrease pesticide use, GMOs confer pesticideresistance to plants thereby allowing for farmers to greatly increase pesticide application. Such dramatically higher concentrations of pesticides will ultimately increase 
pesticide ingestion and exposure to humans, the carcinogenic consequences of which will manifest over time.

\subsection{Increased Cancer Rates}

Herbicide-resistant GMO crops confer tolerance of crops to pesticides, such as glyphosate, resulting in increased application of such pesticides. The long-term consequences include increased pesticide resistance among weeds and other organisms, and increased cancer rates among exposed humans and animals. Glyphosate-resistant weeds are increasing rapidly since the introduction of GMOs [11]. Such consequences increase the costs of controlling resistant weeds, with herbicide costs increasing nearly 3-fold [11].

Increased cancer rates due to the dramatically higher levels of pesticides used since the advent of GMOs pose the greatest long-term threat. A recent study demonstrated an association of pesticide exposure with the development of non-Hodgkins lymphoma [18]. The risk of lymphoma from exposure to glyphosate, the most widely used herbicide, showed an odds ratio of 2.7 in humans [18]. In mouse studies, this pesticide was also shown to cause hepatocellular carcinoma, leukemia and lymphoma [18]. The pesticide has been shown to cause cytotoxicity and mutagenicity in human cells [19]. Similar carcinogenic effects have been reported for other classes of pesticides [18]. Given that the interval between exposure and development of cancer is on the order of years, the cancer rates due to increased pesticide application resulting from GMOs will become evident in the near future.

\subsection{Ecological Toxicity}

Non-target organisms are exposed to and ingesting the transgene toxins of GMO plants. For example, the prototype of GMO is Bt corn, which contains a gene from Bacillus thuringiensis, which is toxic to insects. Inadvertently, this Cry1 Ab endotoxin has been taken up by other non-target arthropods, either by feeding on contaminated insects or by direct feeding on GMO plants [20]. The penetration of these toxins into aquatic streams and organisms has also been demonstrated [21]. With respect to Bt toxin, a significant decrease in survival of aquatic organisms exposed to the transgenic toxin has been reported [22]. Thus, GMO toxins are entering ecosystems far beyond the crops that are modified and into disparate organisms and food chains, elevating the risk of concentration of toxins over time, as was the case with toxic pesticides in prior decades.

\section{Conclusion}

In summary, GMO use in agricultural crops has risen rapidly to comprise the vast majority of crops grown in the US, such that they are present in up to $90 \%$ of US foods. Currently, consumers are not informed of the presence of GMOs in foods. Accumulating evidence demonstrating the toxicity of GMO foods in animals, including carcinoma formation, liver and kidney disease and significantly higher death rates, demonstrate likely health risks to humans associated with ingestion of GMO foods. In addition, contrary to the argument put forth for GMO use, the introduction of pesticide-resistant GMO crops has resulted in a dramatic increase in the application of pesticides. Increased pesticide application since GMOs were introduced has been shown spur on the development of pesticide-resistant insects, weeds and other organisms, further increasing costs, and to increase cancer rates in humans and animals. The "substantive equivalence" of GMO crops is in question, since they harbor foreign genes and numerous mutations not present in normal crops. Finally, given the evident health risks, future consequences, and economic incentives by large companies holding GMO patents, the consumers' right to know provides a highly compelling public health and ethical argument for mandatory labeling of GMO-containing foods in the US.

\section{Acknowledgements}

The authors gratefully acknowledge Dr. Noel Armenakas for his assistance with the writing of this manuscript.

\section{REFERENCES}

[1] United States Department of Agriculture, Economic Research Service, "Adoption of Genetically Engineered Crops in the U.S.," 2012.

www.ers.usda.gov/data-products/adoption-of-geneticallyengineered-crops-in-the-us/documentation.aspx

[2] T. M. Klein, E. D. Wolf, R. Wu and J. C. Sanford, "High-Velocity Microprojectiles for Delivering Nucleic Acids into Living Cells,” Nature, Vol. 327, 1987, pp. 7073.

http://www.nature.com/nature/journal/v327/n6117/abs/32 7070a0.html doi:10.1038/327070a0

[3] N. G. Halford and P. R. Shewry, "Genetically Modified Crops: Methodology, Benefits, Regulation and Public Concerns,” British Medical Bulletin, Vol. 56, No. 1, 2000, pp. 62-73. doi:10.1258/0007142001902978

[4] Monstanto, "Product Patents," 2013. http://www.monsanto.com/products/Pages/product-patent s.aspx

[5] OECD, "Report of the Workshop on the Toxicological and Nutritional Testing of Novel Foods," 1997. http://www.oecd.org

[6] FAO, "Report of a Joint FAO/WHO Expert Consultation on Allergenicity of Foods Derived from Biotechnology," Food and Agriculture Organisation of the United Nations, Rome, 2001. 
[7] H. A. Kuiper, G. A. Kleter, H. P. Noteborn and E. J. Kok, "Assessment of the Food Safety Issues Related to Genetically Modified Foods,” The Plant Journal, Vol. 27, No. 6, 2001, pp. 503-528. doi:10.1046/j.1365-313X.2001.01119.x

[8] E. J. Kok and H. A. Kuiper, "Comparative Safety Assessment of Biotech Crops," Trends in Biotechnology, Vol. 21, No. 10, 2003, pp. 439-444. doi:10.1016/j.tibtech.2003.08.003

[9] G.-E. Seralini, E. Clair, R. Mesnage, S. Gress, N. Defarge, M. Malatesta, D. Hennequin and J. S. de Vendomois, "Long Term Toxicity of a Roundup Herbicide and a Roundup-Tolerant Genetically Modified Maize,” Food and Chemical Toxicology, Vol. 40, No. 8, 2012, pp. 1432-1436. doi:10.1016/j.fct.2012.08.005

[10] J. S. de Vendomois, F. Roullier, D. Cellier and G.-E. Seralini, "A Comparison of the Effects of Three GM Corn Varieties on Mammalian Health,” International Journal of Biological Sciences, Vol. 5, No. 7, 2009, pp. 706-726. doi:10.7150/ijbs.5.706

[11] C. Benbrook, "Impacts of Genetically Engineered Crops on Pesticide Use in the US-The First Sixteen Years," Environmental Sciences Europe, Vol. 24, 2012, pp. 1-13. http://www.enveurope.com/content/24/1/24 doi:10.1186/2190-4715-24-24

[12] J. R. Latham, A. K. Wilson and R. A. Steinbrecher, "The Mutational Consequences of Plant Transformation," Journal of Biomedicine and Biotechnology, Vol. 2006, 2006, Article ID: 25376. doi:10.1155/JBB/2006/25376

[13] M. Labra, C. Savini and M. Bracale, "Genomic Changes in Transgenic Rice (Oryza sativa L.) Plants Produced by Infecting Calli with Agrobacterium tumefaciens," Plant Cell Reports, Vol. 20, No. 4, 2001, pp. 325-330. doi:10.1007/s002990100329

[14] Food and Drug Administration, Office of Nutrition, Labeling and Dietary Supplements, "Guidance for Industry: A Food Labeling Guide,” 1994. http://www.fda.gov/food/guidancecomplianceregulatoryin formation/guidancedocuments/foodlabelingnutrition/ucm 059098.htm

[15] C. A. Carter and G. P. Gruere, "Mandatory Labeling of Genetically Modified Foods: Does It Really Provide Con- sumer Choice?” Ag Bio Forum, Vol. 6, No. 1 \& 2, 2013, pp. 68-70.

http://www.agbioforum.org/v6n12/v6n12a13-carter.htm

[16] J. Fernandez-Cornejo, “The Seed Industry in U.S. Agriculture (Agriculture Information Bulletin No. 786),” United States Department of Agriculture Economic Research Service, pp. 1-71. http://www.ers.usda.gov/media/260729/aib786_1_.pdf

[17] Y. B. Liu, B. E. Tabashnik, T. J. Dennehy, A. L. Patin and A. C. Bartlett, "Development Time and Resistance to Bt Crops,” Nature, Vol. 400, No. 6744, 1999, pp. $487-$ 598.

http://www.nature.com/nature/journal/v400/n6744/pdf/40 0519a0.pdf doi:10.1038/22919

[18] L. Hardell and M. Eriksson, "A Case-Control Study of Non-Hodgkin Lymphoma and Exposure to Pesticides," Cancer, Vol. 85, No. 6, 1999, pp. 1353-1360. doi:10.1002/(SICI)1097-0142(19990315)85:6<1353::AID -CNCR19>3.0.CO;2-1

[19] V. J. Koller, M. Furhacker, A. Nersesyan, M. Misik, M. Eisenbauer and S. Knasmeuller, "Cytotoxic and DNADamaging Properties of Glyphosate and Roundup in Human Buccal-Derived Epithelial Cells," Archives of Toxicology, Vol. 86, No. 5, 2012, pp. 805-813. doi:10.1007/s00204-012-0804-8

[20] J. D. Harwood, W. G. Wallin and J. J. Obrycki, "Uptake of Bt Endotoxins on Higher Order Arthropod Predators: Molecular Evidence from a Transgenic Corn Agroecosystem,” Molecular Ecology, Vol. 14, No. 9, 2005, pp. 2815-2823. doi:10.1111/j.1365-294X.2005.02611.x

[21] E. J. Rosi-Marshall, J. L. Tank, T. V. Royer, M. R. Whiles, M. Evans-White, C. Chambers, N. A. Griffiths, J. Pokelsek and M. L. Stephen, "Toxins in Transgenic Crop Byproducts May Affect Headwater Stream Ecosystems," Proceedings of the National Academy of Sciences of the USA, Vol. 104, No. 41, 2007, pp. 16204-16208. doi:10.1073/pnas.0707177104

[22] K. R. Prihoda and J. R. Coats, “Aquatic Fate and Effects of Bacillus thuringiensis Cry3Bb1 Protein: Toward Risk Assessment," Environmental Toxicology and Chemistry, Vol. 27, No. 4, 2008, pp. 793-798. doi:10.1897/07-300.1 